\title{
REVIEW
}

\section{Angiogenesis and angiocrines regulating heart growth}

\author{
Karthik Amudhala Hemanthakumar ${ }^{1,2}$ and Riikka Kivelä (101,2 \\ 1Stem cells and Metabolism Research Program, Research Programs Unit, Faculty of Medicine, University of Helsinki, Helsinki, Finland \\ 2Wihuri Research Institute, Helsinki, Finland
}

Correspondence should be addressed to R Kivelä: riikka.kivela@helsinki.fi

\begin{abstract}
Endothelial cells (ECS) line the inner surface of all blood and lymphatic vessels throughout Key Words the body, making endothelium one of the largest tissues. In addition to its transport function, endothelium is now appreciated as a dynamic organ actively participating in angiogenesis, permeability and vascular tone regulation, as well as in the development and regeneration of tissues. The identification of endothelial-derived secreted factors, angiocrines, has revealed non-angiogenic mechanisms of endothelial cells in both physiological and pathological tissue remodeling. In the heart, ECs play a variety of important roles during cardiac development as well as in growth, homeostasis and regeneration of the adult heart. To date, several angiocrines affecting cardiomyocyte growth in response to physiological or pathological stimuli have been identified. In this review, we discuss the effects of angiogenesis and EC-mediated signaling in the regulation of cardiac hypertrophy. Identification of the molecular and metabolic signals from ECs during physiological and pathological cardiac growth could provide novel therapeutic targets to treat heart failure, as endothelium is emerging as one of the potential target organs in cardiovascular and metabolic diseases.
\end{abstract}

\section{Introduction}

The heart acts as a muscular pump in the hub of a closed blood vascular system to transport oxygenated blood and nutrients to various organs, and to direct the deoxygenated blood to the right ventricle to be re-oxygenated in the lungs. In addition to cardiomyocytes, the heart is composed of multiple cell types: endothelial cells, vascular smooth muscle cells, pericytes, fibroblasts, leukocytes and purkinje fibers, which are embedded in the extracellular matrix (ECM). The different cell types communicate in a multi-directional manner via paracrine factors, direct cell-cell contacts by receptor-ligand binding, adhesion molecules or by forming complexes with ECM to modulate cardiac homeostasis, growth and regeneration.
It is now recognized that the endothelium is much more than only a transport system for blood flow and that endothelial cells (ECs) play a variety of important roles during cardiac development and in growth and homeostasis of the adult heart. The adult human body is estimated to contain at least one trillion endothelial cells, which would cover a surface area of more than 3000 square meters (1). Thus, the endothelium constitutes a large organ that extends to all parts of the body forming a dynamic interface with other organs. Organ-specific ECs possess unique structural, functional and phenotypic properties via expression of specific growth factors, chemokines and adhesion molecules $(2,3)$. This reflects 
the varying needs of different organs for example, oxygen and nutrient supply. ECs in the heart, for example, express high levels of fatty acid transporters compared to most other tissues (3).

ECs in the adult heart continuously line the coronary vasculature and cardiac chambers and are interconnected by junctional proteins forming tight junctions, cadherin junctions and gap junctions to maintain vascular integrity, homeostasis, and barrier function. ECs are metabolically active, control vasomotor tone, regulate angiogenesis, and establish a bidirectional communication between other cardiac cell types by paracrine signaling mechanisms. Indigenously, ECs are the largest cell population in the adult mouse heart by number, as the adult mouse heart was shown to be composed of endothelial cells $\sim 42 \%$, cardiomyocytes (CMs) $\sim 35 \%$, resident mesenchymal cells (fibroblasts and others) $\sim 18 \%$ and leukocytes $\sim 5 \%$ (4). Cardiac ECs and endocardial cells act as sensors for systemic circulating factors and for cardiac stress, and via paracrine signaling they establish an instructive niche to regulate cardiac growth and function (5).

The EC-derived signaling via the release of paracrine/ juxtacrine-acting growth factors, termed as angiocrines (6), is now appreciated to be highly organ specific. Angiocrine signaling has been shown to be essential for physiological growth and homeostasis as well as regeneration in several tissues, such as liver, lungs, bone and the heart $(6,7,8,9$, $10,11,12,13)$. Angiocrines have an important role also in pathological conditions for example, in inflammation and cancer (14), and thus could provide novel targets to treat several diseases. So far, there is very little data on the tissue-specificity of angiocrines. It is highly likely that, like transcriptomes, also the angiocrine profiles of ECs in different tissues vary substantially. Identification of tissuespecific angiocrines could provide novel and specific targets for the treatment of various diseases such as heart failure. Endothelial cell isolation and single-cell RNA sequencing have recently provided important novel information about the heterogeneity of ECs between and within the tissues. From this rapidly expanding data, candidates for tissuespecific angiocrines can be derived. In addition, one can envision combining high-throughput metabolomic and proteomic technologies to screen for EC-derived factors in different physiological and pathological conditions. The validation and functional relevance could be then tested in cellular co-culture models and in transgenic animal models. It is likely that angiocrines work in concert with each other, and a combination of angiocrines rather than single factors would result in more effective and physiological therapies.
There are excellent recent reviews on the crosstalk between endothelial cells and parenchymal cells in various tissues $(14,15,16,17,18)$. In this review, we focus on how ECs regulate cardiomyocyte (CM) growth and cardiac homeostasis. We summarize the known mediators of the endothelial-to-cardiomyocyte interaction and discuss how angiogenesis regulates physiological and pathological heart growth. The list of cardiac angiocrines is expected to expand in the near future, as the methods to screen and identify factors produced in small amounts improve rapidly.

\section{Cardiac hypertrophy and vascular growth}

The heart grows extensively during development via both hyperplasia and hypertrophy of the cardiomyocytes. In adulthood, the heart size remains rather stable, but the heart still retains its capacity for adaptive growth in response to chronic increase in workload to maintain required cardiac output. Cardiac hypertrophy in adults can be caused by physiological or pathological stimuli or due to genetic disorders. Physiological hypertrophy is induced by increased workload during pregnancy or exercise training (19). It is reversible and accompanied with normal or enhanced cardiac function and metabolic activity. On the other hand, pathological hypertrophy develops in response to cardiac overload due to for example, hypertension, myocardial infarction, valve dysfunction or genetic factors. It is part of the complex pathological cardiac remodeling accompanied by impaired contractile function, fibrosis, apoptosis, and upregulation of fetal gene expression, and it contributes to heart failure related mortalities $(20,21)$.

In healthy growth and homeostasis of the myocardium, CM growth must be accompanied by angiogenesis to expand the coronary vasculature to ensure adequate supply of oxygen and nutrients to CMs. In physiological hypertrophy, the heart preserves its oxygen supply by matching the proportional increases in cardiomyocyte size and the extent of angiogenesis (22) mainly by producing vascular endothelial growth factors, which regulate the growth of new and larger blood vessels (23). In pathological states, cardiomyocyte hypertrophy is associated with a mismatch between oxygen supply and demand, as the increased cardiomyocyte size is not matched by a corresponding increase in the vasculature, resulting in cardiac underperfusion and hypoxia (22). It has been demonstrated that inhibiting angiogenesis during overload-induced cardiac hypertrophy results in early development of heart failure $(24,25,26)$. In contrast, induction of angiogenesis delays the onset of heart failure

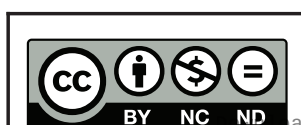

This work is licensed under a Creative Commons Attribution-NonCommercial-NoDerivatives 4.0 International License. ded from Bioscientifica.com at $04 / 26 / 2023$ 04:22:55AM 
in pressure-overload hypertrophy (27). This suggests that the mismatch between $\mathrm{CM}$ growth and angiogenesis promotes the transition from adaptive to pathological hypertrophy followed by progression to heart failure.

Angiogenesis in the heart is regulated by the balance of angiogenic and anti-angiogenic factors produced by cardiomyocytes, fibroblasts, inflammatory cells and endothelial cells. The CM-secreted factors are called cardiokines, among them the vascular endothelial growth factors (VEGFs), angiopoietins (Ang1 and Ang2), hepatocyte growth factor (HGF) and fibroblast growth factors (FGFs), which bind to their receptors on the EC surface and stimulate angiogenesis (28). The VEGFs and VEGF receptors play an indispensable role during embryogenesis to induce vasculogenesis, blood- and lymphangiogenesis. Until now, five VEGF ligands VEGF/VEGF-A, VEGF-B, VEGF-C, VEGF-D and placental growth factor (PlGF) have been identified, and they bind to their appropriate tyrosine kinases receptors VEGFR1/Flt1, VEGFR2/KDR/ Flk1 and VEGFR3/Flt4 present on endothelial cell surface (29). The VEGF receptors are dimerized and activated upon respective ligand binding. The receptors can form homo- or heterodimeric complexes to mediate their effects by autoor transphosphorylation of the tyrosine kinase domains, to further activate the intracellular downstream targets (30).

Insufficient vessel growth and abnormal vessel regression lead to cardiac ischemia and heart failure. To treat these patients, the potential of angiogenic gene therapy and therapeutic vascular growth has been tested in several small and large animal models as well as in clinical trials (reviewed in (31)). Even though the trials have demonstrated increased vascularity, very few have resulted in improved cardiac function with clinical significance so far in human patients, which is partly due to non-optimal gene transfer efficiency and duration, but also to the fact that one single factor may not be enough for the development of functional and durable vasculature. With better understanding of the molecular mechanisms regulating the crosstalk between different cardiac cell types combined with improved gene delivery methods, we will be able to design more efficient therapies to treat cardiovascular diseases.

\section{Angiogenesis-mediated cardiac hypertrophy}

A key observation from the angiogenic gene therapy studies in the heart was made by Michael Simons' group in 2007, when they observed that angiogenesis could induce cardiomyocyte hypertrophy in the absence of any other external stimuli (32). In their study, temporal expression of a secreted angiogenic growth factor PR39 in cardiomyocytes resulted in vascular growth, which was associated with an increase in cardiac mass. This demonstrated that an increase in coronary vasculature in the normal heart leads to increased cardiac mass and myocardial hypertrophy paralleled by increased cardiac performance, even in the absence of a hemodynamic stimulus. The concept of angiogenesis-driven regulation of organ size was first demonstrated in prostate in 1998 (33). The paper was accompanied with an editorial by Judah Folkman, where he proposed a general mechanism by which normal tissue mass may be regulated by the paracrine effect of microvascular endothelial cells (34).

Angiogenesis-induced cardiac hypertrophy has been now observed in several studies using either cardiomyocytespecific transgenic or adeno-associated viral (AAV) vectortreated mice overexpressing either VEGF-B or PIGF as well as in EC-specific VEGFR1 deleted mice $(13,35,36,37,38$, $39,40)$. Cardiac hypertrophy was also reported in mice overexpressing VEGF in the heart (41). The use of VEGF as a therapeutic tool, however, has proven to be tricky, as long-term VEGF administration promotes vascular permeability and immature angiogenesis forming nonfunctional vessels. The same holds true for VEGF-C, whereas overexpression of VEGF-B, PIGF or VEGF-D seems to be rather safe. In our studies, we have used AAV vectors encoding all of the five VEGF family members in pre-clinical mouse and rat models. With VEGF and VEGF-C, the titration has proven to be very difficult, and even with low dose local administration, the new vessels are leaky and immature, and the mice often have to be killed (42). In contrast, overexpression of VEGF-B, PIGF or VEGF-D result in modest increase in the vasculature in many tissues, and there is no massive angiogenesis or leakage but rather an enlargement of the existing vessels $(13,37,42,43)$. Interestingly, both VEGF and VEGF-C are essential during development $(44,45,46)$, while the knockout mice for VEGF-B, PIGF and VEGF-D are healthy and viable $(47,48,49,50)$. These observations indicate safer and larger therapeutic window for these three latter growth factors. Below we discuss more closely the effects of VEGF-B and PlGF, which have been shown to induce angiogenesis-related cardiac hypertrophy.

\section{Vascular endothelial growth factor-B}

VEGF-B was discovered in 1996, and it shares high structural similarities with VEGF and PIGF (51). VEGF-B undergoes

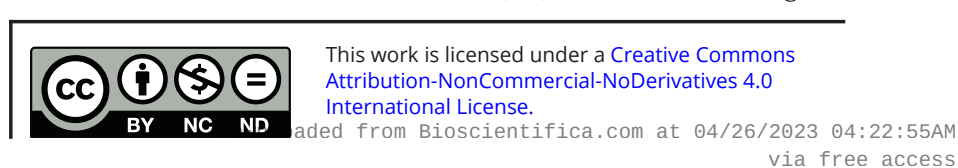


alternative splicing to generate two isoforms VEGF-B167 and VEGF-B186. The VEGF-B167 contains heparin-binding domain and binds to heparin sulfate proteoglycans (HSPGs) on the cell surface, whereas VEGF-B186 isoform does not contain heparin-binding domain making it more soluble (52). Both isoforms bind to membrane-bound and soluble VEGFR1. The proteolytically processed form of VEGF-B186 at Arg-127 can also bind to Neuropilin 1. VEGF-B is highly expressed in metabolically active tissues such as the heart, skeletal muscle and adipose tissue (53). In the heart, one strain of the VEGF-B-knockout mice was proposed to have atrio-ventricular conduction abnormality characterized by prolonged PQ interval (48) and the other strain showed slightly decreased heart size during development (47). However, in a subsequent analysis these phenotypes were not confirmed (54). Cardiomyocyte-specific transgenic overexpression of full-length VEGF-B induced expansion of the coronary vasculature, enlargement of myocardial capillaries, mild cardiomyocyte hypertrophy, and promoted in vivo ischemia protection $(13,36,37,55)$. Importantly, the vascular effects did not include vascular leakage, unlike with VEGF overexpression. Intramyocardial adenoviral or AAV-mediated overexpression of VEGF-B167 in the rat heart prevented progression of angiotensin II associated left ventricular dysfunction (56) and promoted antiapoptotic effect in cardiomyocytes after myocardial infarction without significant effect on vasculature (40). In dogs, intramyocardial or intravascular delivery of AAV9VEGF-B167 preserved diastolic and contractile function and attenuated ventricular chamber remodeling, halting the progression from compensated to decompensated heart failure $(57,58)$. Administration of AAV9-VEGF-B186 also maintained cardiac function by inducing angiogenesis and blocking apoptosis after transaortic constriction in mice (59). It has also been suggested that VEGF-B directly improves myocardial contractility and CM survival by binding to VEGFR1 on CMs (40). Recent studies, however, have demonstrated that the expression of VEGFR1 and VEGFR2 are restricted to ECs in the heart, and there is very low expression in CMs $(13,37,60)$. In the heart, increased VEGF-B expression levels activate AKT/mTORC1 and ERK1/2 MAPK pathways, likely in both ECs and CMs, resulting in vascular and cardiomyocyte growth $(13,37,42)$.

\section{Placental growth factor}

PlGF is encoded by the PGF gene. The mice lacking PlGF are viable and develop normally during embryogenesis, but under pathological conditions such as ischemia, inflammation, wound healing and cancer the PlGFdeficient mice had defective blood vessel growth (49). In humans, PlGF is expressed as four isoforms PlGF1, PlGF2, PlGF3, PlGF4, whereas in mice only one isoform (PlGF2) is expressed (61). Initially, PlGF was found to be expressed in human placenta and its expression is also detected for example, in lungs, skeletal muscles and the heart $(53,61)$. Both PIGF and VEGF-B have high binding affinity for VEGFR1, but PlGF is able to promote VEGFR1 phosphorylation effectively, whereas VEGF-B has very little effect $(62,63)$. This together with their different tissue expression patterns might explain the differences in biological functions. In the mouse heart, PlGF has been found to induce angiogenesis and to mediate cardiac hypertrophy via nitric oxide (NO)-dependent Akt/ mTORC1 pathway (38). In another study, PlGF was found to induce pressure overload-mediated cardiac angiogenesis and adaptive hypertrophy through paracrine signaling between CMs, ECs and fibroblasts (39).

\section{VEGFR2-ERBB signaling in cardiac hypertrophy}

Notably, exogenous administration of PR39, VEGF-B or PlGF failed to induce hypertrophic effect on cultured neonatal cardiomyocytes highlighting that vasculature growth and paracrine signaling from EC to CM are essential (32, 39). PlGF-induced CM growth was shown to be partly attenuated by nitric oxide blocking, indicating that NO is one of the mediators of the EC-CM crosstalk. In our recent study, we demonstrated that VEGF-B or PlGF-induced cardiac angiogenesis and hypertrophy were completely blocked by genetically or pharmacologically inhibiting VEGFR2 signaling, but in contrast, further enhanced by VEGFR1 deletion (13). VEGFR2 activation is known to lead to NO production by ECs (64), thus VEGFR2 activation could explain the partial effects of NO blocking. The observations comply with the proposed role for VEGFR1 as a decoy receptor for $\operatorname{VEGF}(65,66,67)$. When the extracellular domain of the VEGFR1 is deleted or its ligands VEGF-B and PIGF are overexpressed, the binding of VEGF to VEGFR1 is prevented and this renders more endogenous VEGF available to bind and activate VEGFR2, the main angiogenic receptor (Fig. 1). However, the important difference between this indirect activation of VEGFVEGFR2 signaling and VEGF overexpression models is that indirect VEGFR2 activation is restricted by endogenous VEGF levels, preventing immature vessel growth and leakage seen with supraphysiological VEGF doses.

This work is licensed under a Creative Commons Attribution-NonCommercial-NoDerivatives 4.0 International License. ded from Bioscientifica.com at 04/26/2023 04:22:55AM 


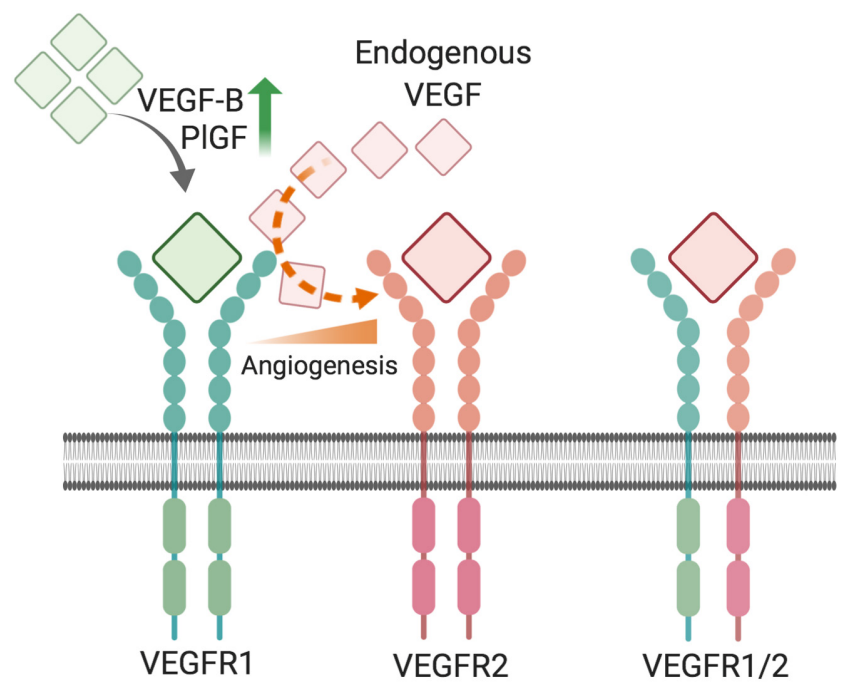

Figure 1

Indirect activation of VEGFR2 by VEGF-B and PIGF and decoy function of VEGFR1. VEGFR1 has 10-fold higher binding affinity to VEGF than VEGFR2, but much weaker activation, thus it has been shown to act mainly as a decoy receptor for VEGF. Increase in levels of VEGF-B or PIGF, which only bind to VEGFR1, displace VEGF from VEGFR1 increasing the availability of endogenoous VEGF to bind to and activate VEGFR2, which leads to angiogenesis. Note that this activation of VEGF-VEGFR2 signaling is limited by the endogenous levels of VEGF, and thus does not induce immature vessel growth and leakage compared to overexpression models of VEGF.

In addition to $\mathrm{NO}$, what else could mediate the VEGFR2 signaling effect from EC to CM? We screened for potential mediators by identifying secreted factors with endothelial expression from the transcriptomics data of the VEGF-B overexpressing hearts. We tested several candidates, and out of them we found increased levels of heparin-binding EGF-like growth factor (HB-EGF) and Adam12, a metalloprotease required for HB-EGF cleavage. Enhanced ERBB1/EGFR and ERBB4 phosphorylation was coupled with increased endothelial VEGFR2 activation during angiogenesis-induced physiological hypertrophy (13). In vitro and in vivo experiments demonstrated that VEGF-B or VEGF stimulation increased the expression and/ or shedding of (HB-EGF) and neuregulin-1 (NRG-1), and enhanced the phosphorylation of EGFR, ERBB4 and AKT.

Neuregulins, HB-EGF and their ERBB tyrosine kinase receptors (ERBB1-4) have been shown to play crucial roles in both the developing and adult cardiovascular system by regulating cardiac development and stress responses. NRG-1 and HB-EGF are released from cardiac microvascular endothelial cells and endocardial endothelium, and they act as paracrine factors via the ERBB receptors expressed in cardiac myocytes. In animal models, deletion of NRG1, ERBB2, or ERBB4 results in embryonic lethality because of the failure of proper cardiac ventricular and valvular development $(68,69,70)$. Most of the HB-EGF-deficient mice die during the first postnatal week and the survivors develop severe heart failure with enlarged ventricular chambers and cardiac valves (71). In adult human heart, left ventricular dysfunction is observed in cancer patients treated with an antibody against ERBB2 (trastuzumab), suggesting cardioprotective effects of ERBB signaling also in humans (72). During the last decade, NRG-1 has been studied extensively in relation to cardiac homeostasis and regeneration. Below we summarize the functions of NRG-1 and HB-EGF in the context of cardiac hypertrophy.

\section{Neuregulin-1}

In heart failure, enhanced activity of NRG-1 emerges as one of the adaptive mechanisms counteracting cardiac remodeling and disease progression (73). The endogenous source of NRG-1 in the heart has been shown largely to be the microvascular and endocardial endothelium (74, 75), and ECs have been demonstrated to be a crucial source of NRG-1 for cardioprotection against ischemic insult (76). NRG-1 induces protein synthesis and hypertrophy of cardiomyocytes through activation of downstream signaling cascades including the ERK1/2 mitogen-activated protein kinase, PI3-kinase, AKT-kinase, mTOR, and FAK (77). These molecular events promote hypertrophic and, at least during development, also mitotic cardiomyocyte growth, as well as cardiomyocyte resistance to apoptosis $(77,78)$. However, in pathological hypertrophy induced by for example, angiotensin IIhypertension model or myocardial infarction, NRG-1 reduces the increase of cardiomyocyte cross-sectional area (73). NRG-1/ERBB signaling is also activated in physiological hemodynamic overload during pregnancy (79) and HB-EGF/NRG-1 expression and shedding are induced by VEGFR2 signaling in angiogenesis-induced physiological cardiac hypertrophy (13). Taken together, NRG-1 induces physiological growth of CMs, while suppressing pathological myocyte growth.

Translational studies have evaluated the potential of NRG-1-ERBB signaling activation in ameliorating ischemia-reperfusion injury and in enhancing cardiac regeneration. In 2017, a human phase 1 clinical study using cimaglermin (NRG-1 $\beta 3$ ) reported improvement in left ventricular function in heart failure patients three months after single-infusion treatment (80). Previously, phase 2 human trials had reported recombinant NRG-1 administration to be safe and to improve cardiovascular function in patients with heart failure $(81,82)$. The effects 
of ERBB signaling in the heart are remarkably pleiotropic with effects on endothelial cells, fibroblasts, macrophages and neuronal cells (73). Thus, the benefits reported with NRG-1 therapy may involve multiple cell types and mechanisms of action in addition to myocyte growth and/or proliferation.

\section{Heparin-binding EGF-like growth factor}

HB-EGF is expressed in several cell types, including ECs, and its activity can be regulated either by expression levels or shedding from the cell surface by metalloproteases $(83,84,85,86)$. The first evidence that secreted HB-EGF regulates cardiomyocyte growth came from studies in isolated adult cardiomyocytes, which were shown to exhibit nearly a two-fold increase in protein content when stimulated with conditioned media from HB-EGF overexpressing COS cells (87). Later, shedding of HB-EGF by ADAM12 was demonstrated to play an important role in the development of cardiac hypertrophy induced by phenylephrine, angiotensin II or endothelin-1 (88). Studies in HB-EGF-null mice provided evidence that HB-EGF is essential for normal cardiac function, as the mice deficient of HB-EGF had enlarged hearts, hypertrophic cardiomyocytes, and abnormal cardiac valves, which led to dilation of cardiac chambers and decreased systolic function (71). The importance of endothelial HB-EGF was demonstrated by its EC-specific deletion, which resulted in cardiac hypertrophy and heart valve malformations, postnatal lethality, resembling the phenotype of HB-EGF-null mice (89). Furthermore, mice expressing uncleavable form of HB-EGF developed dilated cardiomyopathy and severe heart failure, emphasizing the importance of HB-EGF shedding and soluble HB-EGF in the maintenance of cardiac homeostasis (90). On the other hand, cardiomyocyte-specific HB-EGF overexpressing mice demonstrated activation of cardiac fibroblasts and increased fibrosis, but no effect on cardiomyocyte size was observed (91).

To analyze the expression of HB-EGF and NRG-1 in different cardiac EC types, we used the recently published murine EC single-cell RNA sequencing database (https:// www.vibcancer.be/software-tools/ec-atlas) from the Carmeliet lab (92). In the EC atlas database, we first categorized the cardiac EC cell type clusters as blood EC (lyve1- Prox1- Npr3-), Lymphatic EC (lyve1+ Prox1+) and Endocardial cells (Npr3+) based on the previously published markers for different ECs. Then the expression of HB-EGF and NRG-1 were verified in these clusters.
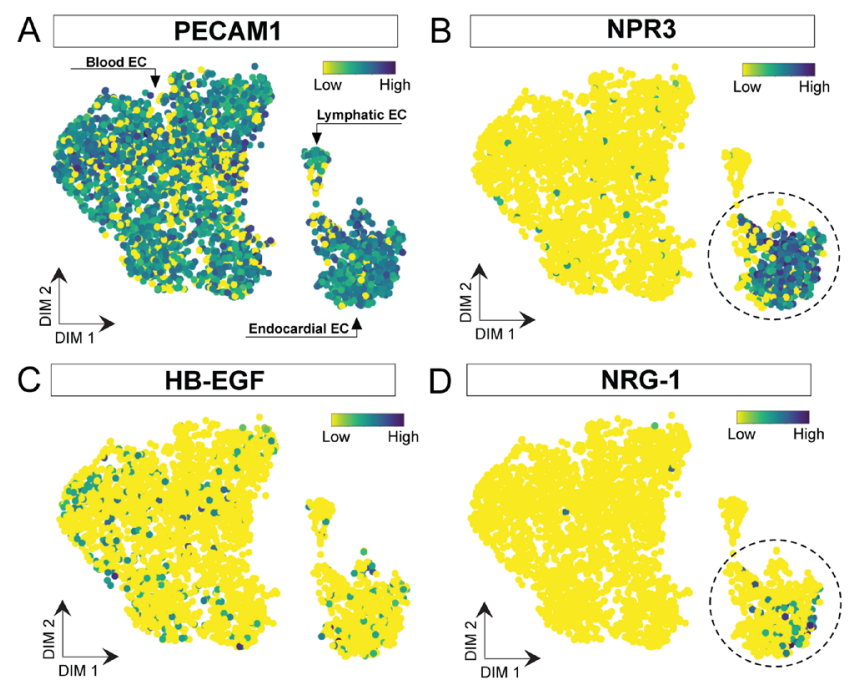

Figure 2

Expression of NRG-1 and HB-EGF in cardiac vascular and endocardial ECs. t-distributed Stochastic Neighbor Embedding (t-SNE) plot showing. (A) The expression of a pan-endothelial cell marker PECAM1 in the blood, lymphatic and endocardial ECs in the adult mouse heart; (B) Endocardialspecific marker NPR3 in the endocardial cluster (inside the dashed-lines); (C and D) HB-EGF and NRG-1 in the vascular and endocardial ECs. To analyze the expression of HB-EGF and NRG-1 in different cardiac EC cell types, a nonlinear dimensionality reduction method was applied to reduce and visualize the multi-dimensional big data in two- or threedimensions (t-SNE). Based on the gene expression profile of single cells, the algorithm clusters the cardiac EC cells with similar and dissimilar gene expression pattern in nearby and distant points with high probability. Our analysis indicates that HB-EGF is expressed throughout all EC clusters, whereas NRG-1 is mainly restricted to endocardial cells. For the analysis, we have used the publicly available single cell mouse cardiac EC atlas (https://www.vibcancer.be/software-tools/ec-atlas) (92).

The results demonstrate that HB-EGF is expressed in all blood ECs, lymphatic EC clusters as well as in endocardial cells, whereas NRG-1 is expressed almost exclusively in the endocardial cells of the adult mice heart (Fig. 2). This suggests that HB-EGF is acting throughout the heart, whereas NRG-1 is mainly involved in the endocardiummyocardium crosstalk.

\section{Other angiocrines regulating cardiomyocyte growth}

In addition to NO and the ERBB ligands, several secreted factors have been shown to regulate cardiomyocyte growth (Table 1). We screened the previously reported factors against our RNA sequencing database from isolated and purified adult mouse cardiac ECs to select those factors, which are produced by ECs. It should be noted that many of these angiocrines are also produced by other cell types and they can also act on non-myocytes, highlighting the 
Table 1 Angiocrines regulating cardiac hypertrophy.

\begin{tabular}{|c|c|c|}
\hline Angiocrine & Effects on cardiomyocytes & References \\
\hline Periostin & $\begin{array}{l}\text { - Periostin overexpression in the heart protected the mice from rupture following } \\
\text { MI and induced hypertrophy with aging. } \\
\text { - In an 8-week TAC mouse model, deletion of periostin decreased cardiac } \\
\text { hypertrophy and fibrosis. } \\
\text { - During the first } 10 \text { days after myocardial infarction the mice lacking periostin were } \\
\text { susceptible to ventricular rupture but the surviving mice showed decreased fibrosis } \\
\text { and better ventricular function. }\end{array}$ & $(99,100)$ \\
\hline TSP-1 & $\begin{array}{l}\text { - TSP-1 levels were increased due to pressure-overload in mice. } \\
\text { - TSP-1 null mice increased MMP3 and MMP9 expression, exhibited sarcomeric loss, } \\
\text { sarcolemma disruption and cardiomyocyte degenerative changes following pressure } \\
\text { overload. } \\
\text { - Loss of TSP-1 in mice induced early cardiac hypertrophy and promoted delayed } \\
\text { dilation in response to pressure overload. }\end{array}$ & $(101,102)$ \\
\hline ADM & $\begin{array}{l}\text { - Adrenomedullin is a pleiotropic peptide that inhibits cardiomyocyte hypertrophy } \\
\text { and cardiac fibroblast proliferation in acute rat myocardial infarction models and in } \\
\text { humans with cardiac disease. } \\
\text { - Plays an important role in vascular integrity and angiogenesis. }\end{array}$ & $(103)$ \\
\hline Midkine & $\begin{array}{l}\text { - Midkine levels are elevated in heart failure (HF) patients and acts as a marker for } \\
\text { stratifying the risk in HF patients. } \\
\text { - Cardiac-specific overexpression of Midkine promoted severe cardiac hypertrophy, } \\
\text { dysfunction and decreased the survival rate of the mice after TAC. }\end{array}$ & $(104,105)$ \\
\hline BMP-4 & $\begin{array}{l}\text { - BMP-4 levels are upregulated during pathological cardiac hypertrophic models and } \\
\text { induces cardiomyocyte hypertrophy and apoptosis. }\end{array}$ & $(106)$ \\
\hline FSTL-1 & $\begin{array}{l}\text { - Acute or chronic overexpression of FSTL-1 increased the AMPK activation in the } \\
\text { myocardium and prevented the TAC-induced hypertrophy and cardiac failure. }\end{array}$ & $(107$ \\
\hline CTGF & $\begin{array}{l}\text { - CTGF activates ERK1/2, p38 MAPK, JNK and Akt signaling cascades and promotes } \\
\text { cardiac hypertrophy. }\end{array}$ & $(108))$ \\
\hline IGF-1 & $\begin{array}{l}\text { - High dose of IGF-1 induced physiological cardiac hypertrophy and positive ionotropic } \\
\text { effect without altering the expression of fetal and myocardial gene expression. }\end{array}$ & (109) \\
\hline APLN & $\begin{array}{l}\text { - Apln acts as a negative regulator of cardiac hypertrophy during ANG II infusion and } \\
\text { promotes myocardial remodeling, fibrosis and results in cardiac dysfunction. } \\
\text { - Exogenous administration of pyr1-apelin13 increases the ACE2 expression, reduces } \\
\text { cardiac hypertrophy and fibrosis in the ANG II-infused ApoE knockout mice. } \\
\text { - Loss of Apln receptor decreases chronic pressure overload induced cardiac } \\
\text { hypertrophy and heart failure. }\end{array}$ & $(110,111,112)$ \\
\hline
\end{tabular}

The list consists of secreted factors produced by cardiac endothelial cells and, which have been demonstrated to regulate cardiomyocyte hypertrophy. The list was first retrieved from the meta-analysis by Segers et al. (17) and the expression in EC was confirmed using our own RNAseq database from isolated adult mouse cardiac ECs.

complexity of multicellular paracrine signaling in the heart.

\section{Endocardium-myocardium crosstalk during heart development}

Endocardium is formed by specialized endothelial cells that line the inner surface of the cardiac chambers. Endocardium is a source of instructive signals for the development of the heart valves and chambers, and the endocardium-myocardium communication is essential for myocardial trabeculation and compaction. Notch signaling pathway has been identified to coordinate cellular interactions during heart development by communicating with other pathways (93), such as
NRG-1 - ERBB (94). HB-EGF has also been identified as an endocardial Notch target and an essential angiocrine regulating cardiac development (95). Hippo signaling is an important regulator of mammalian heart size by controlling cardiomyocyte growth in a cell-autonomous manner (96). Recently, the constituents of Hippo signaling, transcription factors Yap and Taz, were demonstrated to play also an instructive, non-cell-autonomous role in the heart during development. Endocardial Yap and Taz regulated myocardial growth through the release of NRG-1 as a paracrine factor from endocardium to cardiomyocytes (97). Yap/Taz act as mechanical sensors in ECs. They transduce the signals exerted by for example, bloodflow, extracellular matrix stiffness and cardiomyocyte contraction, triggering cellular signaling and angiogenesis (98). It is suggested that mechanotransduction of Yap/

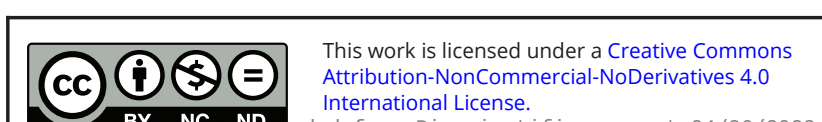

International License.

ded from Bioscientifica.com at 04/26/2023 04:22:55AM 
Taz mediates pathological effects of disturbed blood flow in vascular diseases (98). It is likely that changes in the mechanical cues to ECs in cardiovascular diseases would affect their angiocrine profiles as well. These data indicate that the same pathways are acting both in the developing heart as well as during adult heart growth, however, the role of endocardial paracrine signaling in the adult heart is currently not well understood.

\section{Conclusions}

Considerable knowledge has accumulated over the recent years regarding angiocrine signaling and its role in the regulation of tissue growth, regeneration and homeostasis. Cardiac angiogenesis plays a central role in the development of physiological vs pathological heart growth and the transition to heart failure. It has now been appreciated that it is not only the transport function of the vasculature that is important, but also its active role in paracrine signaling and crosstalk between other cardiac cell types. The understanding of cardiac angiocrines important for cardiomyocyte growth, metabolism and function is of utmost importance for the identification of novel therapeutic targets. In this review we have focused on angiocrines and signaling pathways known to

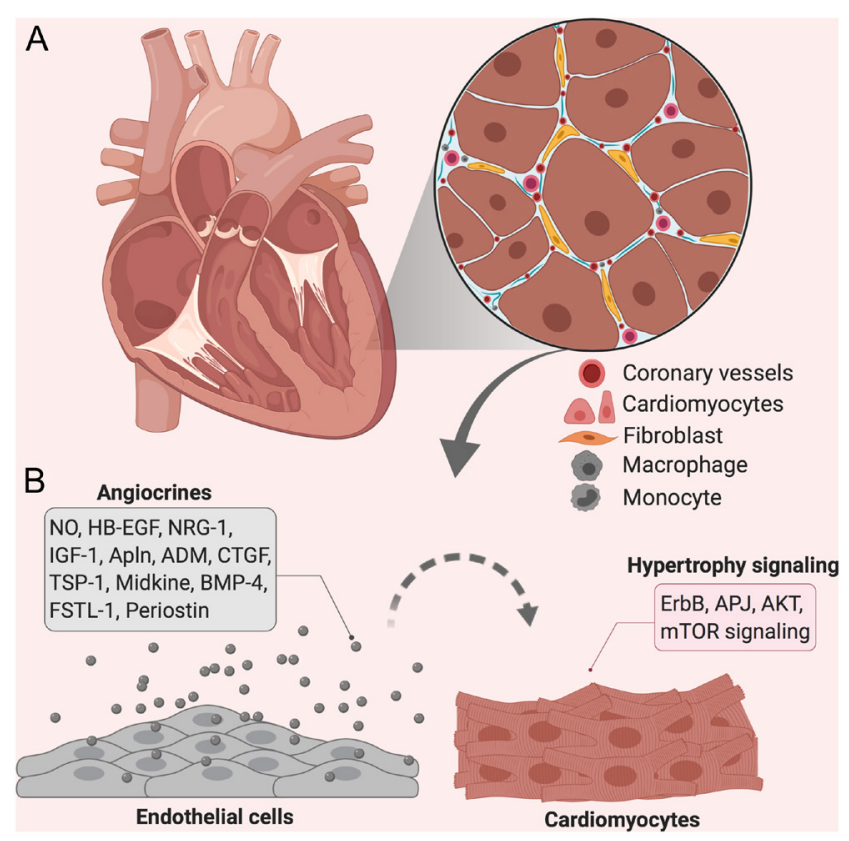

Figure 3

Cardiac cell types and angiocrine-mediated regulation of cardiomyocyte hypertrophy. (A) Tissue architecture and the major cell types present in the adult heart. (B) Angiocrines secreted from cardiac ECs known to participate in hypertrophic signaling and cardiomyocyte growth. modulate CM growth (Fig. 3). In addition to angiocrines, micro RNAs (miRNA) and long non-coding RNAs (lncRNA) are produced and secreted by endothelial cells. These can be taken up by cardiomyocytes, where they can regulate growth and function. Not much is currently known about specific miRNAs and lncRNAs regulating EC-CM interaction, thus we have not covered them in this review. The challenge in the field is still to decipher the fundamental differences in intercellular communication between physiological and pathological cardiac growth, and how the latter proceeds to heart failure, which is a major health problem.

From a clinical perspective, identification of heartspecific angiocrine factors, which would either be produced only by cardiac ECs or have function/activity restricted to cardiomyocytes, could provide specific therapies without side effects in other tissues and cell types. For this, we need advanced studies to learn more about heart-specific ECs and angiocrines.

\section{Declaration of interest}

The authors declare that there is no conflict of interest that could be perceived as prejudicing the impartiality of this review.

\section{Funding}

The authors thank the Jenny and Antti Wihuri Foundation (RK, KAH), Academy of Finland (RK, 297245), the Finnish Foundation for Cardiovascular Research (RK, KAH), the Sigrid Jusélius Foundation (RK), the Finnish Cultural Foundation (RK), the Biomedicum Helsinki Foundation (KAH), and the Aarne Koskelo Foundation (KAH) for funding.

\section{Acknowledgements}

The authors thank Dr Virpi Talman for providing valuable insights during the manuscript preparation. Due to the space limitation, the auth apologize for not including or discussing other significant contributions in the field.

\section{References}

1 Jaffe EA. Cell biology of endothelial cells. Human Pathology 198718 234-239. (https://doi.org/10.1016/s0046-8177(87)80005-9)

2 Aird WC. Endothelial cell heterogeneity. Cold Spring Harbor Perspectives in Medicine 20122 a006429. (https://doi.org/10.1101/ cshperspect.a006429)

3 Nolan DJ, Ginsberg M, Israely E, Palikuqi B, Poulos MG, James D, Ding BS, Schachterle W, Liu Y, Rosenwaks Z, et al. Molecular signatures of tissue-specific microvascular endothelial cell heterogeneity in organ maintenance and regeneration. Developmental Cell 201326 204-219. (https://doi.org/10.1016/j.devcel.2013.06.017) 4 Pinto AR, Ilinykh A, Ivey MJ, Kuwabara JT, D’Antoni ML, Debuque R, Chandran A, Wang L, Arora K, Rosenthal NA, et al. Revisiting

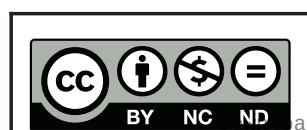

This work is licensed under a Creative Commons Attribution-NonCommercial-NoDerivatives 4.0 International License. 
cardiac cellular composition. Circulation Research 2016118 400-409. (https://doi.org/10.1161/CIRCRESAHA.115.307778)

5 Brutsaert DL. Cardiac endothelial-myocardial signaling: its role in cardiac growth, contractile performance, and rhythmicity. Physiological Reviews 200383 59-115. (https://doi.org/10.1152/ physrev.00017.2002)

6 Ding BS, Nolan DJ, Butler JM, James D, Babazadeh AO, Rosenwaks Z, Mittal V, Kobayashi H, Shido K, Lyden D, et al. Inductive angiocrine signals from sinusoidal endothelium are required for liver regeneration. Nature 2010468 310-315. (https://doi.org/10.1038/ nature09493)

7 Kobayashi H, Butler JM, O’Donnell R, Kobayashi M, Ding BS, Bonner B, Chiu VK, Nolan DJ, Shido K, Benjamin L, et al. Angiocrine factors from Akt-activated endothelial cells balance self-renewal and differentiation of haematopoietic stem cells. Nature Cell Biology 2010 12 1046-1056. (https://doi.org/10.1038/ncb2108)

8 Ding BS, Nolan DJ, Guo P, Babazadeh AO, Cao Z, Rosenwaks Z, Crystal RG, Simons M, Sato TN, Worgall S, et al. Endothelialderived angiocrine signals induce and sustain regenerative lung alveolarization. Cell 2011147 539-553. (https://doi.org/10.1016/j. cell.2011.10.003)

9 Ding BS, Cao Z, Lis R, Nolan DJ, Guo P, Simons M, Penfold ME, Shido K, Rabbany SY \& Rafii S. Divergent angiocrine signals from vascular niche balance liver regeneration and fibrosis. Nature 2014 505 97-102. (https://doi.org/10.1038/nature12681)

$10 \mathrm{Hu}$ J, Srivastava K, Wieland M, Runge A, Mogler C, Besemfelder E, Terhardt D, Vogel MJ, Cao L, Korn C, et al. Endothelial cell-derived angiopoietin-2 controls liver regeneration as a spatiotemporal rheostat. Science $20143 \mathbf{3 4 3}$ 416-419. (https://doi.org/10.1126/ science.1244880)

11 Ramasamy SK, Kusumbe AP, Wang L \& Adams RH. Endothelial Notch activity promotes angiogenesis and osteogenesis in bone. Nature 2014507 376-380. (https://doi.org/10.1038/nature13146)

12 Parodi EM \& Kuhn B. Signalling between microvascular endothelium and cardiomyocytes through neuregulin. Cardiovascular Research 2014102 194-204. (https://doi.org/10.1093/cvr/cvu021)

13 Kivela R, Hemanthakumar KA, Vaparanta K, Robciuc M, Izumiya Y, Kidoya H, Takakura N, Peng X, Sawyer DB, Elenius K, et al. Endothelial cells regulate physiological cardiomyocyte growth via VEGFR2-mediated paracrine signaling. Circulation 2019139 2570-2584. (https://doi.org/10.1161/

CIRCULATIONAHA.118.036099)

14 Pasquier J, Ghiabi P, Chouchane L, Razzouk K, Rafii S \& Rafii A. Angiocrine endothelium: from physiology to cancer. Journal of Translational Medicine 202018 52. (https://doi.org/10.1186/s12967020-02244-9)

15 Rafii S, Butler JM \& Ding BS. Angiocrine functions of organ-specific endothelial cells. Nature 2016529 316-325. (https://doi.org/10.1038/ nature17040)

16 Ramasamy SK, Kusumbe AP \& Adams RH. Regulation of tissue morphogenesis by endothelial cell-derived signals. Trends in Cell Biology 201525 148-157. (https://doi.org/10.1016/j.tcb.2014.11.007)

17 Segers VFM, Brutsaert DL \& De Keulenaer GW. Cardiac remodeling: endothelial cells have more to say Than just NO. Frontiers in Physiology 20189 382. (https://doi.org/10.3389/fphys.2018.00382)

18 Gogiraju R, Bochenek ML \& Schafer K. Angiogenic endothelial cell signaling in cardiac hypertrophy and heart failure. Frontiers in Cardiovascular Medicine 20196 20. (https://doi.org/10.3389/ fcrm.2019.00020)

19 Shimizu I \& Minamino T. Physiological and pathological cardiac hypertrophy. Journal of Molecular and Cellular Cardiology 201697 245-262. (https://doi.org/10.1016/j.yjmcc.2016.06.001)

20 van Berlo JH, Maillet M \& Molkentin JD. Signaling effectors underlying pathologic growth and remodeling of the heart. The Journal of Clinical Investigation 2013123 37-45. (https://doi. org/10.1172/JCI62839)
21 Maillet M, van Berlo JH \& Molkentin JD. Molecular basis of physiological heart growth: fundamental concepts and new players. Nature Reviews Molecular Cell Biology 201314 38-48. (https://doi. org/10.1038/nrm3495)

22 Mohammed SF, Hussain S, Mirzoyev SA, Edwards WD, Maleszewski JJ \& Redfield MM. Coronary microvascular rarefaction and myocardial fibrosis in heart failure with preserved ejection fraction. Circulation 2015131 550-559. (https://doi.org/10.1161/ CIRCULATIONAHA.114.009625)

23 Shiojima I, Sato K, Izumiya Y, Schiekofer S, Ito M, Liao R, Colucci WS \& Walsh K. Disruption of coordinated cardiac hypertrophy and angiogenesis contributes to the transition to heart failure. The Journal of Clinical Investigation 2005115 2108-2118. (https://doi. org/10.1172/JCI24682)

24 Sano M, Minamino T, Toko H, Miyauchi H, Orimo M, Qin Y, Akazawa H, Tateno K, Kayama Y, Harada M, et al. p53-induced inhibition of Hif-1 causes cardiac dysfunction during pressure overload. Nature $2007 \mathbf{4 4 6} 444-448$. (https://doi.org/10.1038/ nature05602)

25 Izumiya Y, Shiojima I, Sato K, Sawyer DB, Colucci WS \& Walsh K. Vascular endothelial growth factor blockade promotes the transition from compensatory cardiac hypertrophy to failure in response to pressure overload. Hypertension 200647 887-893. (https://doi. org/10.1161/01.HYP.0000215207.54689.31)

26 Oka T, Akazawa H, Naito AT \& Komuro I. Angiogenesis and cardiac hypertrophy: maintenance of cardiac function and causative roles in heart failure. Circulation Research 2014114 565-571. (https://doi. org/10.1161/CIRCRESAHA.114.300507)

27 Friehs I, Margossian RE, Moran AM, Cao-Danh H, Moses MA \& del Nido PJ. Vascular endothelial growth factor delays onset of failure in pressure-overload hypertrophy through matrix metalloproteinase activation and angiogenesis. Basic Research in Cardiology 2006101 204-213. (https://doi.org/10.1007/s00395-005-0581-0)

28 Carmeliet P. Angiogenesis in health and disease. Nature Medicine 2003 9 653-660. (https://doi.org/10.1038/nm0603-653)

29 Adams RH \& Alitalo K. Molecular regulation of angiogenesis and lymphangiogenesis. Nature Reviews Molecular Cell Biology 20078 464-478. (https://doi.org/10.1038/nrm2183)

30 Olsson AK, Dimberg A, Kreuger J \& Claesson-Welsh L. VEGF receptor signalling - in control of vascular function. Nature Reviews Molecular Cell Biology 20067 359-371. (https://doi.org/10.1038/nrm1911)

31 Yla-Herttuala S, Bridges C, Katz MG \& Korpisalo P. Angiogenic gene therapy in cardiovascular diseases: dream or vision? European Heart Journal 201738 1365-1371. (https://doi.org/10.1093/eurheartj/ ehw547)

32 Tirziu D, Chorianopoulos E, Moodie KL, Palac RT, Zhuang ZW, Tjwa M, Roncal C, Eriksson U, Fu Q, Elfenbein A, et al. Myocardial hypertrophy in the absence of external stimuli is induced by angiogenesis in mice. The Journal of Clinical Investigation $2007 \mathbf{1 1 7}$ 3188-3197. (https://doi.org/10.1172/JCI32024)

33 Franck-Lissbrant I, Haggstrom S, Damber JE \& Bergh A. Testosterone stimulates angiogenesis and vascular regrowth in the ventral prostate in castrated adult rats. Endocrinology 1998139 451-456. (https://doi. org/10.1210/endo.139.2.5683)

34 Folkman J. Is tissue mass regulated by vascular endothelial cells? Prostate as the first evidence. Endocrinology 1998139 441-442. (https://doi.org/10.1210/endo.139.2.5858)

35 Karpanen T, Bry M, Ollila HM, Seppanen-Laakso T, Liimatta E, Leskinen H, Kivelä R, Helkamaa T, Merentie M, Jeltsch M, et al. Overexpression of vascular endothelial growth factor-B in mouse heart alters cardiac lipid metabolism and induces myocardial hypertrophy. Circulation Research 2008103 1018-1026. (https://doi. org/10.1161/CIRCRESAHA.108.178459)

36 Bry M, Kivela R, Holopainen T, Anisimov A, Tammela T, Soronen J, Silvola J, Saraste A, Jeltsch M, Korpisalo P, et al. Vascular endothelial growth factor-B acts as a coronary growth factor in transgenic rats

This work is licensed under a Creative Commons Attribution-NonCommercial-NoDerivatives 4.0 International License. ded from Bioscientifica.com at 04/26/2023 04:22:55AM 
without inducing angiogenesis, vascular leak, or inflammation. Circulation 2010122 1725-1733. (https://doi.org/10.1161/ CIRCULATIONAHA.110.957332)

37 Kivela R, Bry M, Robciuc MR, Rasanen M, Taavitsainen M, Silvola JM, Saraste A, Hulmi JJ, Anisimov A, Mäyränpää MI, et al. VEGF-Binduced vascular growth leads to metabolic reprogramming and ischemia resistance in the heart. EMBO Molecular Medicine 20146 307-321. (https://doi.org/10.1002/emmm.201303147)

38 Jaba IM, Zhuang ZW, Li N, Jiang Y, Martin KA, Sinusas AJ, Papademetris X, Simons M, Sessa WC, Young LH, et al. NO triggers RGS4 degradation to coordinate angiogenesis and cardiomyocyte growth. The Journal of Clinical Investigation 2013123 1718-1731. (https://doi.org/10.1172/JCI65112)

39 Accornero F, van Berlo JH, Benard MJ, Lorenz JN, Carmeliet P $\&$ Molkentin JD. Placental growth factor regulates cardiac adaptation and hypertrophy through a paracrine mechanism. Circulation Research 2011109 272-280. (https://doi.org/10.1161/ CIRCRESAHA.111.240820)

40 Zentilin L, Puligadda U, Lionetti V, Zacchigna S, Collesi C, Pattarini L, Ruozi G, Camporesi S, Sinagra G, Pepe M, et al. Cardiomyocyte VEGFR-1 activation by VEGF-B induces compensatory hypertrophy and preserves cardiac function after myocardial infarction. FASEB Journal 201024 1467-1478. (https:// doi.org/10.1096/fj.09-143180)

41 Marneros AG. Effects of chronically increased VEGF-A on the aging heart. FASEB Journal 201832 1550-1565. (https://doi.org/10.1096/ fj.201700761RR)

42 Robciuc MR, Kivela R, Williams IM, de Boer JF, van Dijk TH, Elamaa H, Tigistu-Sahle F, Molotkov D, Leppänen VM, Käkelä R, et al. VEGFB/VEGFR1-induced expansion of adipose vasculature counteracts obesity and related metabolic complications. Cell Metabolism 201623 712-724. (https://doi.org/10.1016/j. cmet.2016.03.004)

43 Rasanen M, Degerman J, Nissinen TA, Miinalainen I, Kerkela R, Siltanen A, Backman JT, Mervaala E, Hulmi JJ, Kivelä R, et al. VEGF-B gene therapy inhibits doxorubicin-induced cardiotoxicity by endothelial protection. Proceedings of the National Academy of Sciences of the United States of America 2016113 13144-13149. (https://doi. org/10.1073/pnas.1616168113)

44 Carmeliet P, Ferreira V, Breier G, Pollefeyt S, Kieckens L, Gertsenstein M, Fahrig M, Vandenhoeck A, Harpal K, Eberhardt C, et al. Abnormal blood vessel development and lethality in embryos lacking a single VEGF allele. Nature 1996380 435-439. (https://doi. org/10.1038/380435a0)

45 Ferrara N, Carver-Moore K, Chen H, Dowd M, Lu L, O'Shea KS Powell-Braxton L, Hillan KJ \& Moore MW. Heterozygous embryonic lethality induced by targeted inactivation of the VEGF gene. Nature 1996380 439-442. (https://doi.org/10.1038/380439a0)

46 Karkkainen MJ, Haiko P, Sainio K, Partanen J, Taipale J, Petrova TV, Jeltsch M, Jackson DG, Talikka M, Rauvala H, et al. Vascular endothelial growth factor $\mathrm{C}$ is required for sprouting of the first lymphatic vessels from embryonic veins. Nature Immunology 20045 74-80. (https://doi.org/10.1038/ni1013)

47 Bellomo D, Headrick JP, Silins GU, Paterson CA, Thomas PS, Gartside M, Mould A, Cahill MM, Tonks ID, Grimmond SM, et al. Mice lacking the vascular endothelial growth factor-B gene (Vegfb) have smaller hearts, dysfunctional coronary vasculature, and impaired recovery from cardiac ischemia. Circulation Research 2000 86 E29-E35. (https://doi.org/10.1161/01.res.86.2.e29)

48 Aase K, von Euler G, Li X, Ponten A, Thoren P, Cao R, Cao Y, Olofsson B, Gebre-Medhin S, Pekny M, et al. Vascular endothelial growth factor-B-deficient mice display an atrial conduction defect. Circulation 2001104 358-364. (https://doi.org/10.1161/01. cir.104.3.358)

49 Carmeliet P, Moons L, Luttun A, Vincenti V, Compernolle V, De Mol M, Wu Y, Bono F, Devy L, Beck H, et al. Synergism between vascular endothelial growth factor and placental growth factor contributes to angiogenesis and plasma extravasation in pathological conditions. Nature Medicine 20017 575-583. (https://doi. org/10.1038/87904)

50 Baldwin ME, Halford MM, Roufail S, Williams RA, Hibbs ML, Grail D, Kubo H, Stacker SA \& Achen MG. Vascular endothelial growth factor $\mathrm{D}$ is dispensable for development of the lymphatic system. Molecular and Cellular Biology 200525 2441-2449. (https://doi.org/10.1128/ MCB.25.6.2441-2449.2005)

51 Olofsson B, Pajusola K, Kaipainen A, von Euler G, Joukov V, Saksela O, Orpana A, Pettersson RF, Alitalo K \& Eriksson U. Vascular endothelial growth factor B, a novel growth factor for endothelial cells. Proceedings of the National Academy of Sciences of the United States of America 199693 2576-2581. (https://doi.org/10.1073/ pnas.93.6.2576)

52 Olofsson B, Korpelainen E, Pepper MS, Mandriota SJ, Aase K, Kumar V, Gunji Y, Jeltsch MM, Shibuya M, Alitalo K, et al. Vascular endothelial growth factor B (VEGF-B) binds to VEGF receptor-1 and regulates plasminogen activator activity in endothelial cells Proceedings of the National Academy of Sciences of the United States of America 199895 11709-11714. (https://doi.org/10.1073/ pnas.95.20.11709)

53 Bry M, Kivela R, Leppanen VM \& Alitalo K. Vascular endothelial growth factor-B in physiology and disease. Physiological Reviews 2014 94 779-794. (https://doi.org/10.1152/physrev.00028.2013)

54 Dijkstra MH, Pirinen E, Huusko J, Kivela R, Schenkwein D, Alitalo K \& Ylä-Herttuala S. Lack of cardiac and high-fat diet induced metabolic phenotypes in two independent strains of Vegf-b knockout mice. Scientific Reports 20144 6238. (https://doi.org/10.1038/ srep06238)

55 Lahteenvuo JE, Lahteenvuo MT, Kivela A, Rosenlew C, Falkevall A, Klar J, Heikura T, Rissanen TT, Vähäkangas E, Korpisalo P, et al. Vascular endothelial growth factor-B induces myocardium-specific angiogenesis and arteriogenesis via vascular endothelial growth factor receptor-1- and neuropilin receptor-1-dependent mechanisms. Circulation 2009119 845-856. (https://doi.org/10.1161/ CIRCULATIONAHA.108.816454)

56 Serpi R, Tolonen AM, Huusko J, Rysa J, Tenhunen O, Yla-Herttuala S \& Ruskoaho H. Vascular endothelial growth factor-B gene transfer prevents angiotensin II-induced diastolic dysfunction via proliferation and capillary dilatation in rats. Cardiovascular Research 201189 204-213. (https://doi.org/10.1093/cvr/cvq267)

57 Pepe M, Mamdani M, Zentilin L, Csiszar A, Qanud K, Zacchigna S, Ungvari Z, Puligadda U, Moimas S, Xu X, et al. Intramyocardial VEGF-B167 gene delivery delays the progression towards congestive failure in dogs with pacing-induced dilated cardiomyopathy. Circulation Research 2010106 1893-1903. (https://doi.org/10.1161/ CIRCRESAHA.110.220855)

58 Woitek F, Zentilin L, Hoffman NE, Powers JC, Ottiger I, Parikh S, Kulczycki AM, Hurst M, Ring N, Wang T, et al. Intracoronary cytoprotective gene therapy: a study of VEGF-B167 in a pre-clinical animal model of dilated cardiomyopathy. Journal of the American College of Cardiology 201566 139-153. (https://doi.org/10.1016/j. jacc.2015.04.071)

59 Huusko J, Lottonen L, Merentie M, Gurzeler E, Anisimov A, Miyanohara A, Alitalo K, Tavi P \& Ylä-Herttuala S. AAV9-mediated VEGF-B gene transfer improves systolic function in progressive left ventricular hypertrophy. Molecular Therapy: The Journal of the American Society of Gene Therapy 201220 2212-2221. (https://doi. org/10.1038/mt.2012.145)

60 Kurotsu S, Osakabe R, Isomi M, Tamura F, Sadahiro T, Muraoka N Kojima H, Haginiwa S, Tani H, Nara K, et al. Distinct expression patterns of Flk1 and Flt1 in the coronary vascular system during development and after myocardial infarction. Biochemical and Biophysical Research Communications 2018495 884-891. (https://doi. org/10.1016/j.bbrc.2017.11.094) 
61 De Falco S. The discovery of placenta growth factor and its biological activity. Experimental and Molecular Medicine 201244 1-9. (https:// doi.org/10.3858/emm.2012.44.1.025)

62 Autiero M, Waltenberger J, Communi D, Kranz A, Moons L, Lambrechts D, Kroll J, Plaisance S, De Mol M, Bono F, et al. Role of PlGF in the intra- and intermolecular cross talk between the VEGF receptors Flt1 and Flk1. Nature Medicine 20039 936-943. (https://doi. org/10.1038/nm884)

63 Anisimov A, Leppanen VM, Tvorogov D, Zarkada G, Jeltsch M, Holopainen T, Kaijalainen S \& Alitalo K. The basis for the distinct biological activities of vascular endothelial growth factor receptor-1 ligands. Science Signaling 20136 ra52. (https://doi.org/10.1126/ scisignal.2003905)

64 Kroll J \& Waltenberger J. VEGF-A induces expression of eNOS and iNOS in endothelial cells via VEGF receptor-2 (KDR). Biochemical and Biophysical Research Communications 1998252 743-746. (https://doi. org/10.1006/bbrc.1998.9719)

65 Hiratsuka S, Minowa O, Kuno J, Noda T \& Shibuya M. Flt-1 lacking the tyrosine kinase domain is sufficient for normal development and angiogenesis in mice. Proceedings of the National Academy of Sciences of the United States of America 199895 9349-9354. (https://doi. org/10.1073/pnas.95.16.9349)

66 Shibuya M. Vascular endothelial growth factor receptor-1 (VEGFR-1/ Flt-1): a dual regulator for angiogenesis. Angiogenesis 20069 225-230; discussion 31. (https://doi.org/10.1007/s10456-006-9055-8)

67 Nesmith JE, Chappell JC, Cluceru JG \& Bautch VL. Blood vessel anastomosis is spatially regulated by Flt1 during angiogenesis. Development 2017144 889-896. (https://doi.org/10.1242/dev.145672)

68 Gassmann M, Casagranda F, Orioli D, Simon H, Lai C, Klein R \& Lemke G. Aberrant neural and cardiac development in mice lacking the ErbB4 neuregulin receptor. Nature 1995378 390-394. (https:// doi.org/10.1038/378390a0)

69 Lee KF, Simon H, Chen H, Bates B, Hung MC \& Hauser C. Requirement for neuregulin receptor erbB2 in neural and cardiac development. Nature 1995378 394-398. (https://doi. org/10.1038/378394a0)

70 Meyer D \& Birchmeier C. Multiple essential functions of neuregulin in development. Nature 1995378 386-390. (https://doi. org/10.1038/378386a0)

71 Iwamoto R, Yamazaki S, Asakura M, Takashima S, Hasuwa H, Miyado K, Adachi S, Kitakaze M, Hashimoto K, Raab G, et al. Heparin-binding EGF-like growth factor and ErbB signaling is essential for heart function. Proceedings of the National Academy of Sciences of the United States of America 2003100 3221-3226. (https:// doi.org/10.1073/pnas.0537588100)

72 Slamon DJ, Leyland-Jones B, Shak S, Fuchs H, Paton V, Bajamonde A, Fleming T, Eiermann W, Wolter J, Pegram M, et al. Use of chemotherapy plus a monoclonal antibody against HER2 for metastatic breast cancer that overexpresses HER2. New England Journal of Medicine 2001344 783-792. (https://doi.org/10.1056/ NEJM200103153441101)

73 De Keulenaer GW, Feyen E, Dugaucquier L, Shakeri H, Shchendrygina A, Belenkov YN, Brink M, Vermeulen Z \& Segers VFM. Mechanisms of the multitasking endothelial protein NRG-1 as a compensatory factor during chronic heart failure Circulation. Heart Failure 201912 e006288. (https://doi.org/10.1161/ CIRCHEARTFAILURE.119.006288)

74 Cote GM, Miller TA, Lebrasseur NK, Kuramochi Y \& Sawyer DB. Neuregulin-1alpha and beta isoform expression in cardiac microvascular endothelial cells and function in cardiac myocytes in vitro. Experimental Cell Research 2005311 135-146. (https://doi. org/10.1016/j.yexcr.2005.08.017)

75 Lemmens K, Segers VF, Demolder M \& De Keulenaer GW. Role of neuregulin-1/ErbB2 signaling in endothelium-cardiomyocyte crosstalk. The Journal of Biological Chemistry 2006281 19469-19477. (https://doi.org/10.1074/jbc.M600399200)
76 Hedhli N, Huang Q, Kalinowski A, Palmeri M, Hu X, Russell RR $\&$ Russell KS. Endothelium-derived neuregulin protects the heart against ischemic injury. Circulation 2011123 2254-2262. (https:// doi.org/10.1161/CIRCULATIONAHA.110.991125)

77 Galindo CL, Ryzhov S \& Sawyer DB. Neuregulin as a heart failure therapy and mediator of reverse remodeling. Current Heart Failure Reports 201411 40-49. (https://doi.org/10.1007/s11897-013-0176-2)

78 Tzahor E \& Poss KD. Cardiac regeneration strategies: staying young at heart. Science 2017356 1035-1039. (https://doi.org/10.1126/ science.aam5894)

79 Lemmens K, Doggen K \& De Keulenaer GW. Activation of the neuregulin/ErbB system during physiological ventricular remodeling in pregnancy. American Journal of Physiology. Heart and Circulatory Physiology 2011300 H931-H942. (https://doi.org/10.1152/ ajpheart.00385.2010)

80 Lenihan DJ, Anderson SA, Lenneman CG, Brittain E, Muldowney 3rd JAS, Mendes L, Zhao PZ, Iaci J, Frohwein S, Zolty R, et al. A phase I, single ascending dose study of Cimaglermin Alfa (neuregulin 1beta3) in patients with systolic dysfunction and heart failure. JACC: Basic to Translational Science 20161 576-586. (https://doi.org/10.1016/j. jacbts.2016.09.005)

81 Gao R, Zhang J, Cheng L, Wu X, Dong W, Yang X, Li T, Liu X, Xu Y, Li X, et al. A phase II, randomized, double-blind, multicenter, based on standard therapy, placebo-controlled study of the efficacy and safety of recombinant human neuregulin-1 in patients with chronic heart failure. Journal of the American College of Cardiology 201055 1907-1914. (https://doi.org/10.1016/j.jacc.2009.12.044)

82 Jabbour A, Hayward CS, Keogh AM, Kotlyar E, McCrohon JA, England JF, Amor R, Liu X, Li XY, Zhou MD, et al. Parenteral administration of recombinant human neuregulin-1 to patients with stable chronic heart failure produces favourable acute and chronic haemodynamic responses. European Journal of Heart Failure 201113 83-92. (https://doi.org/10.1093/eurjhf/hfq152)

83 Abraham JA, Damm D, Bajardi A, Miller J, Klagsbrun M \& Ezekowitz RA. Heparin-binding EGF-like growth factor: characterization of rat and mouse cDNA clones, protein domain conservation across species, and transcript expression in tissues. Biochemical and Biophysical Research Communications 1993190 125-133. (https://doi.org/10.1006/bbrc.1993.1020)

84 Yoshizumi M, Kourembanas S, Temizer DH, Cambria RP, Quertermous T \& Lee ME. Tumor necrosis factor increases transcription of the heparin-binding epidermal growth factor-like growth factor gene in vascular endothelial cells. The Journal of Biological Chemistry 1992267 9467-9469.

85 Prenzel N, Zwick E, Daub H, Leserer M, Abraham R, Wallasch C $\&$ Ullrich A. EGF receptor transactivation by G-protein-coupled receptors requires metalloproteinase cleavage of proHB-EGF. Nature 1999402 884-888. (https://doi.org/10.1038/47260)

86 Iwamoto R \& Mekada E. ErbB and HB-EGF signaling in heart development and function. Cell Structure and Function 200631 1-14. (https://doi.org/10.1247/csf.31.1)

87 Perrella MA, Maki T, Prasad S, Pimental D, Singh K, Takahashi N, Yoshizumi M, Alali A, Higashiyama S \& Kelly RA. Regulation of heparin-binding epidermal growth factor-like growth factor mRNA levels by hypertrophic stimuli in neonatal and adult rat cardiac myocytes. The Journal of Biological Chemistry 1994269 27045-27050.

88 Asakura M, Kitakaze M, Takashima S, Liao Y, Ishikura F, Yoshinaka T, Ohmoto H, Node K, Yoshino K, Ishiguro H, et al. Cardiac hypertrophy is inhibited by antagonism of ADAM12 processing of HB-EGF: metalloproteinase inhibitors as a new therapy. Nature Medicine 20028 35-40. (https://doi.org/10.1038/nm0102-35)

89 Nanba D, Kinugasa Y, Morimoto C, Koizumi M, Yamamura H, Takahashi K, Takakura N, Mekada E, Hashimoto K \& Higashiyama S. Loss of HB-EGF in smooth muscle or endothelial cell lineages causes heart malformation. Biochemical and Biophysical Research

This work is licensed under a Creative Commons Attribution-NonCommercial-NoDerivatives 4.0 International License. ded from Bioscientifica.com at 04/26/2023 04:22:55AM 
Communications $2006350315-321$. (https://doi.org/10.1016/j. bbrc.2006.09.060)

90 Yamazaki S, Iwamoto R, Saeki K, Asakura M, Takashima S, Yamazaki A, Kimura R, Mizushima H, Moribe H, Higashiyama S, et al. Mice with defects in HB-EGF ectodomain shedding show severe developmental abnormalities. Journal of Cell Biology 2003163 469-475. (https://doi.org/10.1083/jcb.200307035)

91 Lian H, Ma Y, Feng J, Dong W, Yang Q, Lu D \& Zhang L. Heparinbinding EGF-like growth factor induces heart interstitial fibrosis via an Akt/mTor/p70s6k pathway. PLoS One 20127 e44946. (https://doi. org/10.1371/journal.pone.0044946)

92 Kalucka J, de Rooij LPMH, Goveia J, Rohlenova K, Dumas SJ, Meta E, Conchinha NV, Taverna F, Teuwen LA, Veys K, et al. Single-cell transcriptome atlas of murine endothelial cells. Cell $2020 \mathbf{1 8 0}$ 764-779.e20. (https://doi.org/10.1016/j.cell.2020.01.015)

93 D'Amato G, Luxan G, del Monte-Nieto G, Martinez-Poveda B, Torroja C, Walter W, Bochter MS, Benedito R, Cole S, Martinez F, et al. Sequential Notch activation regulates ventricular chamber development. Nature Cell Biology 201618 7-20. (https://doi. org/10.1038/ncb3280)

94 Lai D, Liu X, Forrai A, Wolstein O, Michalicek J, Ahmed I, Garratt AN, Birchmeier C, Zhou M, Hartley L, et al. Neuregulin 1 sustains the gene regulatory network in both trabecular and nontrabecular myocardium. Circulation Research 2010107 715-727. (https://doi.org/10.1161/CIRCRESAHA.110.218693)

95 MacGrogan D, D'Amato G, Travisano S, Martinez-Poveda B, Luxan G, Del Monte-Nieto G, Papoutsi T, Sbroggio M, Bou V, Gomez-Del Arco $\mathrm{P}$, et al. Sequential ligand-dependent Notch signaling activation regulates valve primordium formation and morphogenesis. Circulation Research 2016118 1480-1497. (https://doi.org/10.1161/ CIRCRESAHA.115.308077)

96 Heallen T, Zhang M, Wang J, Bonilla-Claudio M, Klysik E, Johnson RL \& Martin JF. Hippo pathway inhibits Wnt signaling to restrain cardiomyocyte proliferation and heart size. Science 2011332 458-461. (https://doi.org/10.1126/science.1199010)

97 Artap S, Manderfield LJ, Smith CL, Poleshko A, Aghajanian H, See K, Li L, Jain R \& Epstein JA. Endocardial Hippo signaling regulates myocardial growth and cardiogenesis. Developmental Biology 2018 440 22-30. (https://doi.org/10.1016/j.ydbio.2018.04.026)

98 Boopathy GTK \& Hong W. Role of hippo pathway-YAP/TAZ signaling in angiogenesis. Frontiers in Cell and Developmental Biology 2019749. (https://doi.org/10.3389/fcell.2019.00049)

99 Borg TK \& Markwald R. Periostin: more than just an adhesion molecule. Circulation Research 2007101 230-231. (https://doi. org/10.1161/CIRCRESAHA.107.159103)

100 Oka T, Xu J, Kaiser RA, Melendez J, Hambleton M, Sargent MA, Lorts A, Brunskill EW, Dorn GW, Conway SJ et al. Genetic manipulation of periostin expression reveals a role in cardiac hypertrophy and ventricular remodeling. Circulation Research 2007 101 313-321. (https://doi.org/10.1161/CIRCRESAHA.107.149047)

101 Vanhoutte D \& Heymans S. Thrombospondin 1: a protective "matricellular" signal in the stressed heart. Hypertension 201158 770-771. (https://doi.org/10.1161/HYPERTENSIONAHA.111.176933)
102 Xia Y, Dobaczewski M, Gonzalez-Quesada C, Chen W, Biernacka A, Li N, Li DW \& Frangogiannis NG. Endogenous thrombospondin 1 protects the pressure-overloaded myocardium by modulating fibroblast phenotype and matrix metabolism. Hypertension 201158 902-911. (https://doi.org/10.1161/HYPERTENSIONAHA.111.175323)

103 Kato J \& Kitamura K. Bench-to-bedside pharmacology of adrenomedullin. European Journal of Pharmacology 2015764 140-148. (https://doi.org/10.1016/j.ejphar.2015.06.061)

104 Kitahara T, Shishido T, Suzuki S, Katoh S, Sasaki T, Ishino M, Nitobe J, Miyamoto T, Miyashita T, Watanabe T et al. Serum midkine as a predictor of cardiac events in patients with chronic heart failure. Journal of Cardiac Failure 201016 308-213. (https://doi.org/10.1016/j. cardfail.2009.12.014)

105 Netsu S, Shishido T, Kitahara T, Honda Y, Funayama A, Narumi T, Kadowaki S, Takahashi H, Miyamoto T, Arimoto T et al. Midkine exacerbates pressure overload-induced cardiac remodeling. Biochemical and Biophysical Research Communications 2014443 205-210. (https://doi.org/10.1016/j.bbrc.2013.11.083)

106 Lu J, Sun B, Huo R, Wang YC, Yang D, Xing Y, Xiao X-L, Xie X $\&$ Dong D-L. Bone morphogenetic protein-2 antagonizes bone morphogenetic protein-4 induced cardiomyocyte hypertrophy and apoptosis. Journal of Cellular Physiology 2014229 1503-1510. (https://doi.org/10.1002/jcp.24592)

107 Shimano M, Ouchi N, Nakamura K, van Wijk B, Ohashi K, Asaumi Y, Higuchi A, Pimentel DR, Sam F, Murohara T et al. Cardiac myocyte follistatin-like 1 functions to attenuate hypertrophy following pressure overload. PNAS 2011108 E899-E906. (https://doi. org/10.1073/pnas.1108559108)

108 Hayata N, Fujio Y, Yamamoto Y, Iwakura T, Obana M, Takai M, Mohri T, Nonen S, Maeda M \& Azuma J. Connective tissue growth factor induces cardiac hypertrophy through Akt signaling. Biochemical and Biophysical Research Communications 2008370 274-278. (https://doi.org/10.1016/j.bbrc.2008.03.100)

109 Tanaka N, Ryoke T, Hongo M, Mao L, Rockman HA, Clark RG \& Ross J Jr. Effects of growth hormone and IGF-I on cardiac hypertrophy and gene expression in mice. American Journal of Physiology 1998275 H393-H399. (https://doi.org/10.1152/ ajpheart.1998.275.2.H393)

110 Zhang ZZ, Wang W, Jin HY, Chen X, Cheng YW, Xu YL Song B, Penninger JM, Oudit GY \& Zhong J-C. Apelin Is a Negative Regulator of Angiotensin II-Mediated Adverse Myocardial Remodeling and Dysfunction. Hypertension 201770 1165-1175. (https://doi. org/10.1161/HYPERTENSIONAHA.117.10156)

111 Scimia MC, Hurtado C, Ray S, Metzler S, Wei K, Wang J, Woods CE, Purcell NH, Catalucci D, Akasaka T et al. APJ acts as a dual receptor in cardiac hypertrophy. Nature 2012488 394-398. (https://doi. org/10.1038/nature11263)

112 Parikh VN, Liu J, Shang C, Woods C, Chang AC, Zhao M, Charo DN, Grunwald Z, Huang Y, Seo K et al. Apelin and APJ orchestrate complex tissue-specific control of cardiomyocyte hypertrophy and contractility in the hypertrophy-heart failure transition. American Journal of Physiology Heart and Circulatory Physiology 2018315 H348-H356. (https://doi.org/10.1152/ajpheart.00693.2017)

Received in final form 12 June 2020

Accepted 22 June 2020

Accepted Manuscript published online 23 june 2020 https://vb.bioscientifica.com

https://doi.org/10.1530/VB-20-0006 (c) 2020 The authors Published by Bioscientifica Ltd
This work is licensed under a Creative Commons Attribution-NonCommercial-NoDerivatives 4.0 International License. ded from Bioscientifica com at $04 / 26 / 2023$ 04:22:55 AM 